\title{
HUMAN EXPOSURE TO THE ARTIFICIAL RADIONUCLIDES IN ENVIRONMENT
}

\section{Ivana Vukanac ${ }^{1}$ \\ Aleksandar Kandić \\ Mirjana Đurašević \\ Bojan Šešlak}

Original scientific paper

Institute of Nuclear Sciences “Vinča”, University of Belgrade

Received: 13.07.2012

UDC: 539.163:614.876

Accepted: 29.08.2012

\begin{abstract}
Artificial radionuclides are product of different human activities and their presence in the environment is negative side effect of civilization progress. They have been spread in the environment by events such as nuclear weapon tests, nuclear accidents and by deliberate and negligent discharge of radioactive waste from nuclear and other installation. Once released in to the nature, the artificial radionuclides start to circle in the same manner as naturally occurring ones, and finally they fall out from air and water onto the ground and build into the foodstuff and drinking water resulting in radiation doses to human beings.

The short overview of presence of artificial radioactivity in human environment and its impact on human life is presented in this paper.
\end{abstract}

Key words: Artificial radioactivity; Nuclear probes; Nuclear accidents; Radioactive waste

\section{INTRODUCTION - ORIGIN OF THE ARTIFICIAL RADIOACTIVITY}

Induced radioactivity, also known as man-made radioactivity, was discovered by Irène Curie and Frederic Joliot in 1934. At a beginning of the XX century (1919) Lord Rutherford performed, for the first time, transformation of the ordinarily stable element nitrogen into oxygen $\mathrm{O}-17$ and proton by bombing the nitrogen with natural alpha particles.
Following the first example of the artificial transmutation of the elements, many other transmutations were carried out. Most of the lighter elements up to potassium were transformed, one into another, by alpha particle bombardment, in each case with the emission of a proton ${ }^{30} \mathrm{P},{ }^{27} \mathrm{Si},{ }^{13} \mathrm{~N}$ (Lawrence, 1935).

\footnotetext{
${ }^{1}$ Correspodence to:

Ivana Vukanac, Institute of Nuclear Sciences "Vinča", University of Belgrade

POB 522, 11001 Belgrade, Serbia

E-mail: vukanac@vinca.rs
} 
In those days, scientist reasonably expected that artificial radioactive substances will play a possibly more important role in the physical and biological sciences in the future than the natural radioactive substances had in the past. Also, these new radioactive substances provided wide variety of beta and gamma rays sources, which proved to be of crucial importance in nuclear medicine applications.

However, the development of this field in physics, in the mid-twentieth century, was mainly connected with the military application of nuclear power (Alexakhin, 2005).

Artificial radionuclides can also be created in nuclear fission processes, discovered in late thirties of XX century. This discovery, in which Serbian scientiest Pavle Savić had a significant role, had a crucial influence on the use of nuclear energy for peaceful purposes, mainly in power generation in nuclear power plants.

Since about 1940, a set of new elements with atomic numbers over 92 (the atomic number of the heaviest naturally occurring element, Uranium) have been artificially made, mainly in neutron capture reactions. They are known as the transuranium elements - $\quad{ }_{93}^{237,239} \mathrm{~Np},{ }_{93}^{238,239,240,241} \mathrm{Pu},{ }_{95}^{241} \mathrm{Am},{ }_{94}^{242,244} \mathrm{Cm}$ and can be detected in the environment due to their release into the environment as a consequence of different human activities (Vukanac, 2008).

Today, the principle of production of artificial radioactive isotopes essentially remained the same, but the development of science and technology in general allow wider choice of targets and beams for bombing in order to create heavier artificial nuclei. More than 1000 artificial radionuclides are known today, and the heaviest is with atomic number 118 (Oganessian et al., 2006). Besides in great research facilities (JINR Dubna, Rusia, GANIL, France, etc.), in any public facility whose activity involves some kind of nuclear engagement processes of creating artificial radioactivity is constantly happening in induced nuclear reactions.

\section{PATHWAYS OF MAN-MADE RADIONU- CLIDES FROM ITS PLACE OF ORIGIN TO THE HUMAN ENVIRONMENT}

Each conscienceless use of radioactive materials or improper disposal of nuclear waste can lead to undesired presence of radioactive isotopes in the environment. The main sources of artificial radioactivity in the human environment were underground and surface nuclear weapons tests and nuclear accidents accompanied by the radioactivity release into the environment.

In the past several decades, especially after the Chernobyl accident, radiological situation gave a rise to an accelerated development of specific ecology area - radioecology. In the late 1950's and early 1960's, radioecology dealt primarily with the impact of nuclear weapons tests (mainly in the atmosphere), which had resulted in a global radioactive contamination of the biosphere (Fig. 1). Thus, the man-made radionuclides dispersed in the environment (fission products, nuclides with induced activity, fissile radionuclides) were incorporated into the trophic chains of migration in the deposition-soil (water)-plant-animal-man system (Alexakhin, 2005).

\section{EVENTS THAT MADE THE DIFFERENCE}

In nuclear accidents great amounts of radioactivity could be released in environment. Majority of nuclear accidents occurred in past several decays had local or regional character, but some of them had a global influence.

Among the first were the accident at a radiochemical military plant "Mayak" in the South Urals, USSR, and Windscale accident in Sellafield, UK, both in 1957. In accident in Windscale facility, connected with malfunctions at a nuclear reactor for weapon grade plutonium production, approximately 0.6$1 \mathrm{PBq}{ }^{131} \mathrm{I}, 22-94 \mathrm{TBq}{ }^{137} \mathrm{Cs}, 5 \mathrm{TBq}{ }^{89} \mathrm{Sr}, 0.22 \mathrm{TBq}$ ${ }^{90} \mathrm{Sr}, 8.8 \mathrm{TBq}{ }^{210} \mathrm{Po}, 5 \mathrm{PBq}{ }^{3} \mathrm{H}$ and $1.6 \mathrm{GBq}{ }^{239} \mathrm{Pu}$ was spread over the northern Europe, mainly Great Britain. 
Further, satellite on the assistant nuclear power SNAP-9A exploded in the upper layer of the southern hemisphere atmosphere and released about $1 \mathrm{~kg}$ of ${ }^{238} \mathrm{Pu}$. Another satellite (KOSMOS-1402) with $50 \mathrm{~kg}$ of $90 \%$ enriched uranium exploded and fell down in southern Atlantic an Indian ocean (Stricht and Kirchmann, 2001; Vukanac, 2008).

Chernobyl accident in April 1986 was classified as the most severe one in the history of nuclear power engineering, since the greatest amount of radioactivity was released and contamination was spread on great surface on the northern hemisphere. Total released activity during this accident was estimated to be $50 \mathrm{PBq}$ for ${ }^{137} \mathrm{Cs}$, and of the same order of magnitude for other released radionuclides, including the alpha emitting isotopes of plutonium, neptunium and curium (Vukanac, 2008).

In the period from 1945-1980, 809 nuclear explosion were performed. Aboveground nuclear probes injected the great amounts of radioactivity in atmosphere. Nuclear weapon tests were performed in several locations: Semipalatinsk and Novaya Zemlya test sites in the USSR, Nevada test site in the USA, Marshall Islands in the Pacific Ocean, Maralinga area in Australia, etc. It is estimated that $11.7 \mathrm{PBq}$ of ${ }^{239} \mathrm{Pu}$ were dispersed over the earth surface. Total density of deposited activity in region from $40^{\circ}-50^{\circ}$ n.g.a. was from $1.5 \mathrm{~Bq} / \mathrm{m}^{2}$ to $700 \mathrm{~Bq} / \mathrm{m}^{2}$ for plutonium isotopes and few thousand $\mathrm{Bq} / \mathrm{m}^{2}$ for radionuclides with shorter half lives (Cathen, 1984).

Long-term consequence of atmospheric nuclear weapons testing in the 1950's and early 1960's is residual fallout that still can bee detected. Atmospheric testing is now banned by most nations. The average dose from residual fallout is about $20 \mu \mathrm{Sv}$ in a year, which represents approximately $1 \%$ of average annual dose, excluding the medical exposure.

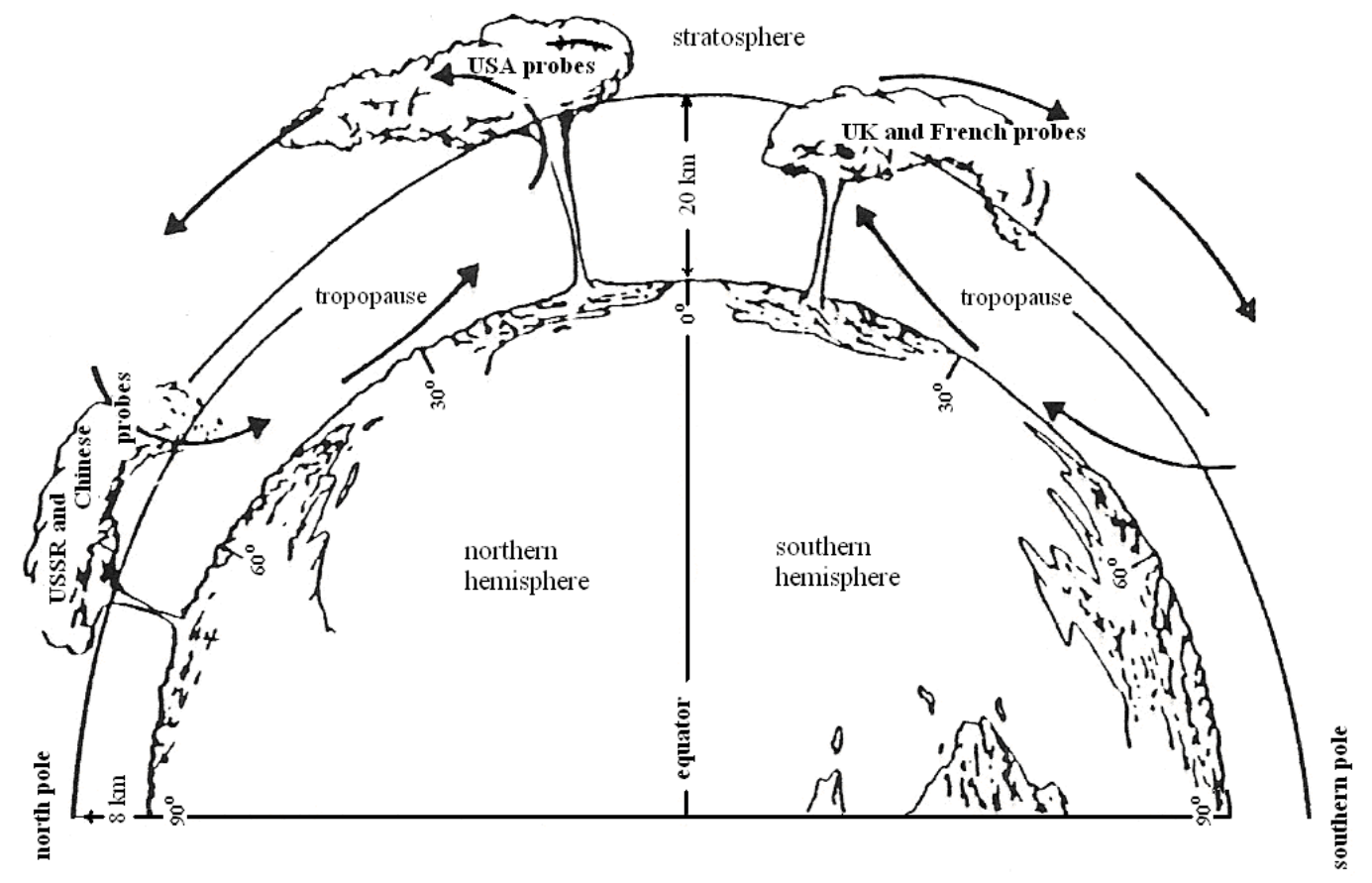

Figure 1. Global radioactive contamination due to nuclear weapon tests

Additionally, there are some regions where the natural amount of uranium isotopes has been "enriched" by depleted uranium, originated from different kinds of projectiles used in performed military actions in $2^{\text {nd }}$ half of $X X$ century (Karangelos et al., 2004, pp. 295-310). 
The most recent accident was when, less than two years ago, on March 11, 2011 strong earthquake followed by the tsunami caused the nuclear accident in Fukushima Daiichi nuclear power plant in Japan. In order to avoid elevation of pressure in reactor core and spent fuel pools, large amount of radioisotopes of relatively low boiling temperature was released. Also, hydrogen explosion occurred and destroy reactor outer building and released radioactive substances in the environment. The highly contaminated air plume caused the local radiological contamination with the rather high value. Consequences, regarding the radiological pollution of local as well as global importance, are subject of many investigations and surveys in environmental protection field, and yet need to be precisely determined.

Besides in nuclear accidents, radioactivity is present in the environment due to conscienceless nuclear waste disposals, cases of lost nuclear submarines, accidents involving the nuclearpowdered aircrafts, different kind of "orphan" sources, etc.

The great variety of radionuclides can be present in nuclear waste material, depending on its origin. Disposal of different types of nuclear waste is very strictly regulated by international legislation.

\section{CURRENT RADIOLOGICAL SITUATION}

Population exposure to the natural and artificial sources of ionizing radiation is presented in the Fig. 2.

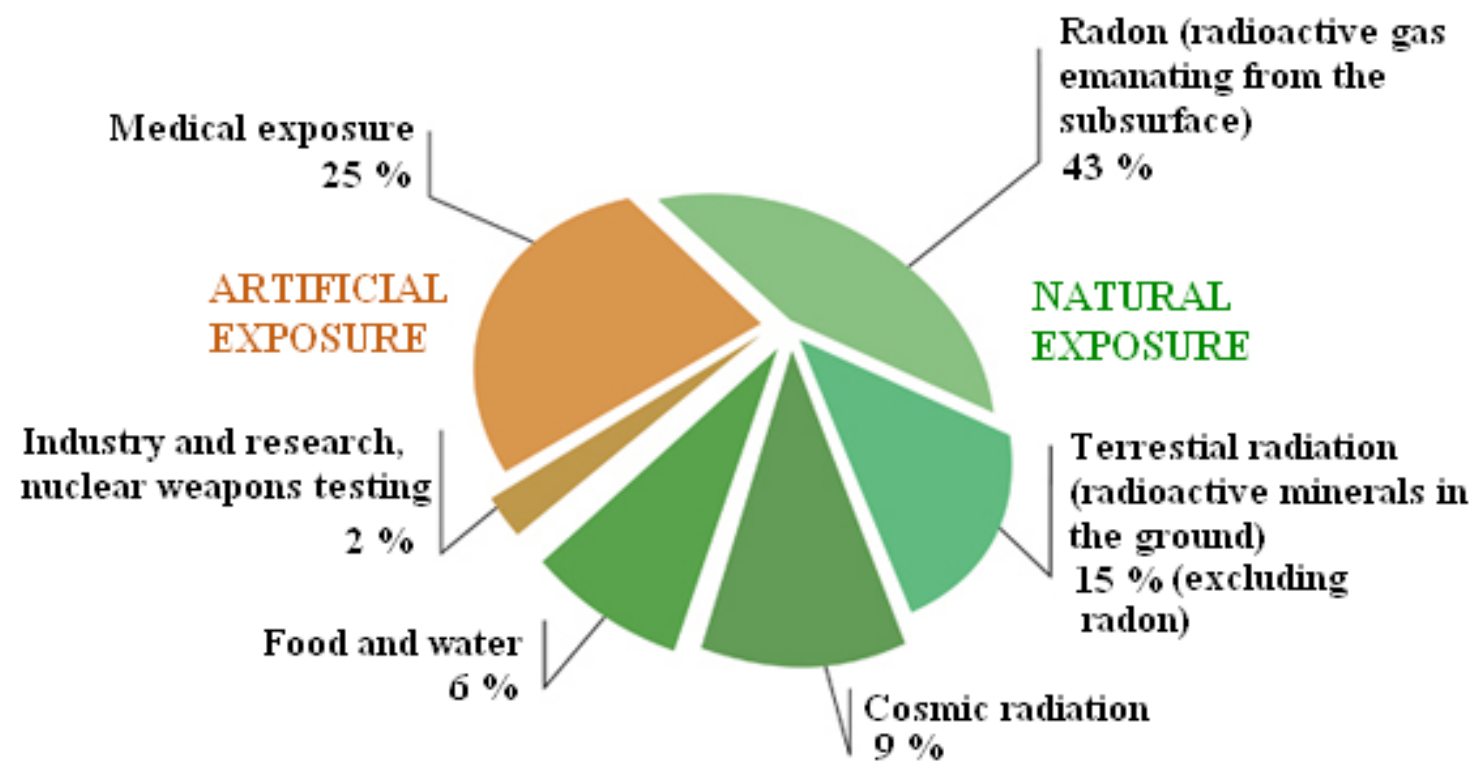

Figure 2. Graphic illustration of natural and artificial exposure

In spite to the frightening quantities of activity released in environment, as it can be seen from the Fig. 2 , total exposure of the population to the artificial radioactivity is less than a third of the overall exposure. Most of this exposure is due to medical purposes, which is conducted under controlled conditions. 
A small part of the exposure to the artificial radioactivity comes from radionuclides used in industry and R\&D activities. Besides in controlled conditions, general population is exposed to the relatively small amounts of radioactivity that can not be controlled and completely predicted. For example, plant growth on contaminated soil or inadequate and excessive use of phosphate fertilizer, can lead to the enhanced intake of radionuclide and thus presents a dangerous and random risk to a human health.

Nowadays, radioecology is a comprehensive scientific discipline with main task to determine correlations among pollutants, pollutant migration, dose from exposure to living organisms and exposure effect. Also, solving the problems connected with the "radiation legacy" (remediation of territories previously affected by radioactive contamination) is one of the challenges of modern radioecology.

\section{ACKNOWLEDGEMENTS}

This work was financially supported by the Serbian Ministry of Education and Science (project number 171018).

\section{REFERENCES}

Alexakhin, R. M. (2005). Radioecology: History and State-ofthe art at the Beginning of the $21^{\text {th }}$ century, Proceedings of the NATO Advanced Research Workshop on Impact of Radiation Risk Estimates in Normal and Emergency Situations, 8-11, 159-168. Yerevan, Armenia.

Cathen, R. I. (1984). Readioactivity in the Environment: Sources, Distribution and Surveillance.

Karangelos, D. J., Anagnostakis, M. J., Hinis, E. P., Simopoulos, S. E. and Žunić, Z. (2004). Determination of depleted Uranium in Environmental Samples by Gamma-spectroscopic techniques, Journal of Environmental Radioactivitz,76. Lawrence, E. O. (1935). Artificial radioactivity, The Ohio Journal of Science. v35 n5, 388-405, ISSN 0030-0950, http://hdl.handle.net/1811/2762

Oganessian Yu. TS. et al. (2006). Synthesis of the isotopes of elements 118 and 116 in ${ }^{249} \mathrm{Cf}$ and ${ }^{245} \mathrm{Cm}+{ }^{48} \mathrm{Ca}$ fusion reactions, Physical Review C 74, 044602

Van Der Stricht E. and Kirchmann, R. (2011). Radioecology Radioactivity \& Ecosystems, A project of the INTERNATIONAL UNION OF RADIOECOLOGY $<$ B-4020, Liege, Belgium.

Vukanac, I. (2008). Determination of the specific alpha activity in the environmental samples by semiconductor spectrometry, PhD thesis, Serbia, Belgrade: University of Belgrade. 